\title{
Research on Multimodal Visual Narrative of Digital Interactive Picture Books
}

\author{
Interaction and Narrative*
}

\author{
Tao Xie \\ Academy of Fine Arts \\ Huanggang Normal University \\ Huanggang, China 438000
}

\author{
Zhiyuan Long \\ Chibi Middle School \\ Huanggang, China 438000
}

\begin{abstract}
Interactive picture books are an extension and development of traditional picture books in the digital media, owning multimodal characteristics such as 3D audio \& video, multidimensional control as well as nonlinear visual narratives. Based on the multimodal discourse analysis, visual grammar, visual narrative frame as well as situated cognition theory, this article discusses the form and pattern for the visual narratives in the interactive picture book, aiming to provide theoretical basis references for the image understanding and narrative design.
\end{abstract}

Keywords-interactive picture books; multimodal; visual grammar; visual narrative; interactive design

\section{INTRODUCTION}

Going with the continuous popularity of all kinds of intelligent terminal devices and mobile applications, online digital reading has been increasingly becoming a habitual tendency for users to access information. Interactive picture books, represented by digital picture books Apps, rise gradually on smart phones, tablet PCs and so on, relying on the diverse and 3D audio-visual languages and touch sensor interaction, which bring users brand-new reading experience, especially the function of joint participation in the interactive narrative, the interactive picture books are widely popular in children and adult users. Based on the picture narrative, the interactive picture books, as a multimedia reading, adopt a variety of audio-visual languages to narrate stories, showing higher multimodal characteristics. Based on the multimodal analysis of the interactive picture books, this article borrows the visual grammar and visual narrative structure theories, as well as the situated cognition theory so as to discuss the form and pattern for visual narrative in the interactive picture books, which may help readers to understand the deeper connotation of storylines, besides, the views about the visual narrative may also inspire designers to perfect the design of the interactive picture books.

\section{MUltimOdAL CHARACTERISTICS AND ANALYSIS OF INTERACTIVE PICTURE BOOKS}

Modality mainly refers to the communication channels and media, such as language, technique, image, color and

*Fund Program: Huanggang Normal University Youth Scientific Research Fund Program (No. 2014021803). music [1]. The interactive picture books realize interaction with readers through symbols and tools such as text, image, sound, picture and motion, which are mainly expressed by three forms namely vision, hearting and touch. When discussing how to express the multimodal phenomena, Kress and Van Leeuwen (1996) raised the grammar of visual design theory framework, which created a visual discourse analysis theory [2] on the basis of representational, interactive and compositional. Seen from the multimodality of interactive picture books, the representational meaning is shown as narrative, which is a reaction and process of languages and psychologies; the interactive meaning is involved in viewpoint, mood, attitude and situation, which are shown as the interaction between designer, picture books and readers; the compositional meaning shown as visual performance, including schema form, information value that visual organs acquire and its significance.

Differing from traditional paper-based picture books, the digital interactive picture books are involved in diverse scene factors, including complicated visual narrative, event relation, image shaping and emotional representation, which consist of multimodal components and are shown through interaction with readers. Facing the scene, the visual grammar, which is applicable for single image analysis, is inadequate to completely interpret the interactive picture books. Going with the continuously expanded multimodality of visual media, more and more scholars have tried to modify and perfect the visual grammar, of whom, Painter, Martin \& Unsworth (2013) raised that the visual narrative frame should be much focused on analyzing the images' ideographic function and interactive relations as well as the role of images in developing the narrative, which was considered a development and makeup to the visual grammar [3]. Relying on the visual grammar theory and researches on the visual narrative analysis framework [4], this article conducts an overall analysis and discussion on the visual narrative of the interactive picture books, showing factors for the multimodal structure of the interactive picture books "Table I", which may help correctly analyze the narrative discourse meaning of the picture books as a whole. 
TABLE I. Multimodal Structure ANALysis of InTERACTIVE PICTURE

\begin{tabular}{|c|c|c|}
\hline Visual Grammar & $\begin{array}{c}\text { Modal } \\
\text { Component }\end{array}$ & Visual Representation \\
\hline \multirow{3}{*}{$\begin{array}{l}\text { Representational } \\
\text { meaning }\end{array}$} & Character & Designer, role and reader \\
\hline & Event relation & $\begin{array}{l}\text { Scene development, } \\
\text { interactive process, behavior } \\
\text { process, thinking process, } \\
\text { reaction process }\end{array}$ \\
\hline & $\begin{array}{l}\text { Background } \\
\text { relation }\end{array}$ & $\begin{array}{ll}\begin{array}{l}\text { Environmental } \\
\text { orientation shift }\end{array} & \text { structure, } \\
\end{array}$ \\
\hline \multirow{3}{*}{$\begin{array}{l}\text { Interactive } \\
\text { meaning }\end{array}$} & Focus system & Subject view, objective view \\
\hline & $\begin{array}{l}\text { Emotional } \\
\text { system }\end{array}$ & $\begin{array}{l}\text { Emotional involvement, } \\
\text { emotional alienation, attitude } \\
\text { and mood }\end{array}$ \\
\hline & $\begin{array}{l}\text { Atmosphere } \\
\text { system }\end{array}$ & $\begin{array}{l}\begin{array}{l}\text { Tone (warmth), color system, } \\
\text { chromaticity } \\
\text { contextualization } \\
\text { harmony }\end{array} \\
\end{array}$ \\
\hline \multirow{3}{*}{$\begin{array}{l}\text { Compositional } \\
\text { meaning }\end{array}$} & $\begin{array}{l}\text { Compositional } \\
\text { meaning }\end{array}$ & $\begin{array}{l}\text { Information value, request, } \\
\text { viewing and significance }\end{array}$ \\
\hline & Layout & $\begin{array}{l}\text { Mixed, complementary, } \\
\text { deeper }\end{array}$ \\
\hline & Visual form & $\begin{array}{l}\text { Picture, line, shape, shadow, } \\
\text { weigh, space and color }\end{array}$ \\
\hline
\end{tabular}

\section{GRAPHIC EXPRESSION AND VISUAL NARRATIVE OF} INTERACTIVE PICTURE BOOKS

\section{A. Multimodal Image Reading and Narrative Representation}

The factors of visual discourse in traditional picture books are mainly text, schema and picture, and a linear picture narrative process is adopted to develop the story, and readers participate in the narrative process via understanding of the abstract, symbolic, and ambiguous and implied meanings. Analyzing from the semiology, "Narratives can compose of various symbolic media, such as written or verbal language, visual image, posture and action, and a combination of the above" [5]. The interactive picture books adopt a combination of text, image, sound, picture, animation and touch technology, which present a multimodal image, and reader may read at different levels and dimensions, the linear narrative allows reader to understand the picture books by different ways and obtain reading experience in exploration, discovery and supplement.

Readers read the interactive picture books through touching the electronic screen, and the contents presentation of the picture books is a dynamic process going and deepening with the interaction and a process of visual guide and infiltration, to which, readers show more subjectivity and emotional input. The narrative representation of the interactive picture books consists of reading, reaction psychological changes. The reader's understanding of the multimodal images constitutes the reaction, which then reflects the attitude of the image participants and form the psychological changes finally. The interactive picture books adopt multimodal tools to group the information according to a certain coding rule to form a multimodal discourse that can show complete interactive meaning and realize the interactive effect as expected, studying what to show from the story structure, situational factors and interactive behaviors and how to show from the narrative subject of images and narrative perspective". During the reading of the interactive picture books, readers receive and decode the information such as interactive meaning and intention to achieve the interactive purposes. To use multi-dimensional organs to experience, feel and understand things is a born ability of human being, and the multimodal interaction better meets the people in the laws of cognition of thins, and diverse modalities of vision, hearing and touch supplement and penetrate each other, jointly showing the narrative themes and conceptual meanings.

\section{B. Emotion Mechanism and Audio-Visual Interaction for Narrative}

The emotions in the visual narratives of the interactive picture books mainly refer to the emotional reaction generated by readers in interaction with the visual images, which consists of two representations namely involvement and alienation. The former refers to the emotion produced by and accompanied with readers when reading, the latter means the readers are not interesting and just reading objectively. The formation of an emotional mechanism plays an important role in showing the interactive meaning of the interactive picture books, which can attract readers to participate to the maximum and keep the picture books open. First of all, visual designs can be used to guide and adjust the perspectives of readers so as to achieve the emotional transmission of the interactive picture books. According to the visual grammar theory one of the important meanings of interaction is contact, which includes not only the actions in reading, but also the eye meeting and viewing selection in the focus system. The spatial narratives of the interactive picture books are much more temporary and random. And users may be free to select the viewpoint and perspective of views, namely experiencing the things through the subjective perspectives of the role in the picture books, the subjective perspectives make readers be better immersed in the storylines, feeling what happens and resonating.

According to the image analysis, modality refers to how a representation of a picture is used, which is shown by color, tone, depth, distinction, harmony and detail (Kress \& Van Leeuwen, 1996). The emotional tone of the interactive picture books can also determined by the color symbol system and the coordination of three attributes of a color namely saturation, color and brightness can create different emotional atmospheres. The highly saturated fresh color shows warmth and energy; the low color gray shows of depression and introverts; the warm color shows kindness and comfort; the cool color shows indifference and alienation; the high brightness shows intimacy and the low brightness shows strangeness and distance. According to the difference in contents and story, the coordination between color components can be used to create different emotional atmospheres.

The emotional involvement can also be intensified by sound and interaction. Appropriate dubbing and background music may stand out glorify the story scene, and multidimensional interactive control is a representation of emotional behaviors as designed, and readers may get deeper 
emotional experience through integrated stimulation on audiovisual organs and body. The App Fantastic Flying Books of Mr. Morris Lessmore, released by Moonbot studio, is an excellent sample of multimodal emotional design "Fig. 1". Interactive technologies with a large number of natural features are adopted in the interactive picture books, which vary with the scene development: hurricanes will appear when readers blow the books in the screen; houses in the air will screw and move correspondingly going with gestures; fingers can be used to play music; pages blank can be written on, and the writing traces will be blown away soon. Some interactive behaviors are achieved through the trigger buttons, and some are natural responses under sensors such as gravity sensor, microphone, camera, gyroscope and more, and the interaction modes are closely matching with the screen scenes and stories. In the second year, the Fantastic Flying Books of Mr. Morris Lessmore released augmented reality (AR)-based book supporting application (book companion APP) "IMAG-NOTRON" version, which connects APP and paper-made picture books, take the camera on the intelligent terminal device over the book, when turning pagers, dynamic scenes with corresponding descriptions will appear on the screen "Fig. 2", where readers feel a more diverse experience in reading.

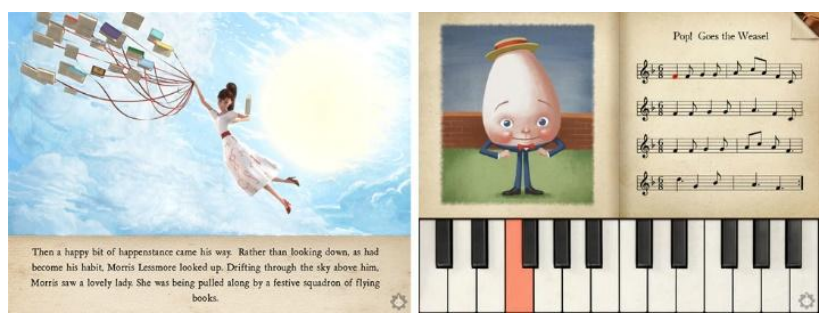

Fig. 1. App Interaction Interface.

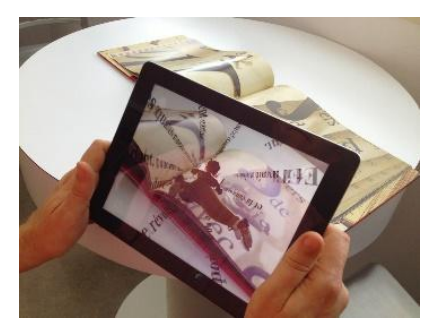

Fig. 2. Function Demo.

In the opinion of psychologist Donald Arthur Norman, "Only at the level of reflection, there is a sense of consciousness and a higher sense of feeling, emotion and perception," says Donald Arthur Norman of the psychologist. "Only this level can experience the full blend of thought and emotion." [6] interactive picture of a variety of modal narrative presentation and real-time conversion, the formation of the stimulus can lead to the reader's positive association and more active exploration, straight feeling, instinctive emotional experience continue to sublimation to the reflection level, to achieve the interactive meaning of the image Profound understanding.

\section{Schema Composition and Visual Aesthetic Narratives}

As far as the narrative way, what the interactive picture books present is a situational visual dimension, which organizes the order and logic of images with a specific visual expression system, relying on the evolution and extension of time and space to narrate stories. Therefore, the visual composition distribution of the interactive picture books has not only differences in space, orientation and order, but also strict visual control in the visual flow.

Seen from the cognition, the schema composition of the interactive picture books is aloes based on the representation and interaction. The composition can be taken as a strategy for reading, and the construction of visual frameworks and highlighting of visual information value may guide readers to read according to the intentions of the image designers. During the image design, usually we should consider reading orders of readers, center of gravity for reading and so on, and the factors with the largest value will be placed on the visual area, which attract most eyeballs. In the meantime, according to the difference in the significance of information value, and schema meaning can be realized through adjusting visual factors on size, proportion, weight, color value, foreground or background position.

The interactive generation is of high dynamics and situation dependency, and the open narration of the interactive picture books also determines the instability of its schema composition. The random reading habits of readers leads to changes of schemas all the time, and it is the uncertainty of reading that shows the unique aesthetic value of the interactive picture books. In order to make readers keep a sense of pleasure in reading, the user interface and interactive design of the interactive picture books have to reach or exceed what the readers have expected. The schema composition and layout shall control the order and depth relationship as a whole, making full use of limited display spaces to achieve the process from function, aesthetics to interactive generation, and the visual factors the schemas shall be kept coordinated, complement and integrated so as to reduce noise or distortion as possible as we can.

The design of interactive picture books shall not only create a clear and visual schema composition, but also set up a visual information indicating system to instruct the reading, spoke from the aesthetic level, it shall show unique visual aesthetics and artistic enthusiasm. Shan Hai Jing is an ancient book of Pre-Qin Dynasty which states ancient geography, property, legends, religion, folklore and the like, full of myths The interactive picture book the Classic of Mountains and Seas is an App that interprets ancient literature through digital technologies "Fig. 3", which is based on the first part "Classic of Mountains: South" of the book, describing a number of exotic plants and animals, of which the visual forms adopt old picture styles, and the background of ancient zithers is empty and simple, full of eastern features, and rich audio-visual contents and reading interaction show a vivid prospect, and the delicate, elegant, fresh styles make readers refreshed. 


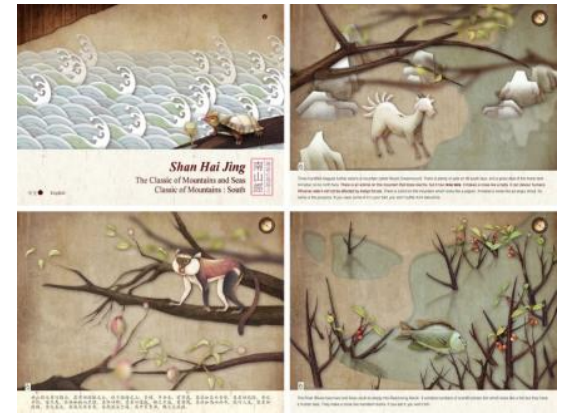

Fig. 3. Interface of the Classic of Mountains and Seas App.

With the electronic touch screen as carrier, the interactive picture book adopts the representation of visual symbol system, setting of interaction and user's participation to create a story space. All kinds of factors such as role object, situation, environment, background, form, size, time and space and so on, of which the organic combination form a rich visual narrative discourse. Though the schema narrative has been taken as the most visual form, yet there are many limitations and shortcomings in the story presentation, emotional substitution and so on. As a multimodal and compound reading medium, the interactive picture books have an incomparable advantage in concepts of representing time expansion and meaning. It not only meets the narrative purposes of visual images, but also strengthens the depth and expansion of visual concepts and thought expression.

\section{EXPANSION OF EMERGING TECHNOLOGIES TO THE VISUAL NARRATIVE LANGUAGE}

The interactive picture books have features such as integration of sound and picture, 3D space, visual interaction, touch screen control and the like, which enhances the reader's emotional experience and aesthetic creation. Facing the extreme pursuit of sensory experience in images, it has caused a design tendency of "stressing interests but neglecting connotations" in the interactive picture books. Some delicate information is covered by digitalization, which cause readers to neglect the cultural connotation, artistry and aesthetic value that the interactive picture books should have. The digitalization is only a form for the interactive picture books to represent, and only the interaction can be the way to communicate with readers, the emerging design technologies are well working to improve the readers' experience in aesthetics and emotion.

Virtual Reality (VR) technology can simulate a virtual three-dimensional space, offering sensor organs of audiovisual and touch, where readers may touch the presence of the stories as if they were there via multi-perception and interactivity. Compared to the complete virtuality of VR, the Augmented Reality (AR) technology can apply the virtual information in interactive picture books to a real world. Real environment and virtual images are overlaid on the same picture or space for co-existence in real time and the interaction is much more natural. Mix Reality (MR) technology merges the real and virtual worlds to create a new visual environment to achieve real-time interaction and coexistence of physical and digital objects. The Cinematic
Reality (CR) technology attempts to project pictures directly into the users' retinas from multiple angles so as to achieve more realistic and virtually indistinguishable images. Depth camera can record visual information of more dimensions, help the terminal devices to identify the distance ... and so on. Technologies have enhanced the simulation to the physical world, during the design and development of the interactive picture books, the application of new cutting-edge technologies greatly expands the forms for visual narratives.

The emerging technologies can not only make the virtual scenes in the interactive picture books full of higher immediacy and immersion, but also satisfy the readers emotionally through sensory experience in vision, auditory sense and touch. Current reading devices are unable to achieve the perception at a physical level, but going with the continuous progress of technologies in the future, more perception functions such as smell and taste will be reflected in the interactive picture book.

\section{CONCLUSION}

Relying on the interaction, supplementation and cooperative relations between multimodal symbols, the interactive picture books have formed significant visual discourses, and the visual grammar and visual narrative analysis theories play an significant role in discussing the cognition rules via the multimodal perspective, it can not only help readers correctly understand the deep connotation of the discourse in the interactive picture books but also enable them to touch the emotion, artistic and aesthetic hidden inside. For designers, the multimodal theory has expanded the angles and ways of thinking of observing things, which help to show the aesthetic value and artistic expression of the interactive picture books, leading the interactive picture books to active changes and continuous development from connotation, form to interactive functions.

\section{ACKNOWLEDGMENT}

This article is supported by Huanggang Normal University Youth Scientific Research Fund Program (No. 2014021803).

Much be obliged!

\section{REFERENCES}

[1] Zhu Yongsheng, Theoretical Basis and Research Methods of Multimodal Discourse Analysis [J]. Foreign Language Research, 2007(5):82-86.

[2] Kress, G. \& van Leeuwen, T. Reading Images: The Grammar of Visual Design [C]. London: Routledge, 1996.

[3] Painter, C. , J . R. Martin \& L. Unsworth . Reading Visual Narratives: Image Analysis of Children's Picture Books [M] . London: Equinox, 2013.

[4] Feng Dezheng, New Development of Visual Grammar: Based on Picture Book Visual Narrative Analysis Frame, Foreign Language Research, 2015, 36(3):23-27.

[5] Cheng Xilin, Introduction to Narrative Theories [J]. Foreign Language Research, 2002(3):10-15.

[6] Donald Arthur Norman, USA, Written by translated by He Xiaomei, Ou Qixing, Design Psychology 3: Emotional Design[M]. Beijing: China CITIC Press, 2015:24. 